\title{
INVENTARISASI ROTAN DI HUTAN LINDUNG DANAU SELOGAN KAPUAS HULU KALIMANTAN BARAT
}

\section{(RATTAN INVENTORY ON PROTECTED FOREST DANAU SELOGAN KAPUAS HULU WEST BORNEO)}

\author{
Yosea Adinata, Syamswisna*, dan Eko Sri Wahyuni
}

Fakultas Keguruan dan IImu Pendidikan, Universitas Tanjungpura

Keywords:

Inventory, Rattan, Protected Forest Danau Selogan

Kata Kunci: Inventarisasi, Rotan, Hutan Lindung Danau Selogan

\begin{abstract}
Rattan has benefits as a raw material for handicrafts such as basket, hats, mats, nyiru, brooms, and binding tools. Danau Selogan Forest has a suitable environment as a place to grow rattan plant. Research about "rattan inventory on protected forest Danau Selogan Kapuas Hulu", Ujung Said Village, Jongkong District, Kapuas Hulu Regency, West Kalimantan Has Been carried out, this study aims to determine the types of rattan that exist in the protected forest of Danau Selogan. This research method is descriptive. Sample were taken using purposive sampling technique with cruising method. Based on the result of the study found 6 species of rattan plants, namely Korthalsia rigida Blume, Calamus pasphalantus Beccari, Daemonorops sabut Beccari, Korthalsia junghuhnii Blume, Calamus caesius Blume, and Korthalsia echinometra Beccari.
\end{abstract}

\section{ABSTRAK}

Rotan mempunyai manfaat sebagai bahan baku kerajinan seperti keranjang, caping, tikar, nyiru, sapu, dan alat pengikat. Hutan Danau Selogan memiliki lingkungan yang cocok sebagai tempat tumbuhnya tanaman rotan. Penelitian tentang "inventarisasi rotan di hutan lindung danau selogan Kapuas Hulu", Desa Ujung Said, Kecamatan Jongkong, Kabupaten Kapuas Hulu, Kalimantan Barat, telah dilaksanakan, penelitian ini bertujuan untuk mengetahui jenisjenis rotan yang ada di hutan lindung Danau Selogan. Metode penelitian ini adalah deskriptif. Sampel diambil menggunakan teknik purposive sampling dengan metode jelajah. Berdasarkan hasil penelitian ditemukan 6 jenis tumbuhan rotan, yaitu Korthalsia rigida Blume, Calamus pasphalantus Beccari, Daemonorops sabut Beccari, Korthalsia junghuhnii Blume, Calamus caesius Blume, dan Korthalsia echinometra Beccari.

"Corresponding Author : syamswisna@fkip.untan.ac.id 


\section{PENDAHULUAN}

Dalam dunia botani tumbuhan rotan menurut Sujoko (2013) adalah tumbuhan dari famili Arecaceae (palem). Rotan rata rata merambat, batangnya berdiameter antara 3-10 centimeter serta berduri, beruas tetapi tidak berongga. Duri ini berfungsi sebagai pertahanan diri serta fasilitas merambat. Rotan merupakan jenis tanaman yang tumbuh di daerah yang beriklim subtropis maupun tropis seperti Indonesia. Habitat tumbuhan rotan pada umumnya berupa daerah tanah berawa, tanah kering hingga pegunungan. Tumbuhan ini pada umumnya tumbuh pada daerah yang memiliki ketinggian 300-1000 mdpl. Rotan tumbuh pada daerah yang memiliki curah hujan 2000$4000 \mathrm{~mm}$ per tahun, tumbuhan ini dapat tumbuh di daerah beriklim basah dengan suhu udara $24-30^{\circ} \mathrm{C}$.

Rotan termasuk jenis tanaman penyusun tumbuhan hutan tropika sehingga tidak memiliki persyaratan tempat tumbuh yang khusus. Penyebaran tanaman rotan di Indonesia hampir meliputi semua pulau, terutama pulau-pulau yang memiliki hutan alam primer ataupun sekunder. Karena rotan merupakan salah satu penyusun formasi hutan tropika, maka pembudidayaannya dianjurkan untuk dilakukan di dalam area hutan (Januminro, 2000).

Rotan mempunyai manfaat sebagai bahan baku kerajinan seperti keranjang, caping, tikar, nyiru, sapu, dan alat pengikat. Hutan Danau Selogan memiliki lingkungan yang cocok sebagai tempat tumbuhnya tanaman rotan.

Kawasan Hutan Lindung Danau Selogan terletak di Desa Ujung Said, Kecamatan Jongkong, Kabupaten Kapuas Hulu yang menjadi salah satu habitat bagi pertumbuhan rotan di wilayah Kalimantan Barat. Hutan Lindung Danau Selogan termasuk kawasan hutan lindung berdasarkan Surat Keputusan Menteri Kehutanan Republik Indonesia No. 67-II tahun 2014 dengan luas 1.240 ha dan teletak pada titik koordinat $0^{\circ} 36^{\prime} 40.06$ " LU dan $112^{\circ} 21^{\prime}$ 56.13" BT (Arsip Desa Ujung Said, 2014). Bentuk topografi Kawasan Hutan Lindung Danau Selogan termasuk daerah dataran rendah dan memiliki berbagai macam tipe hutan seperti hutan sekunder, hutan karangas, dan areal tanah terbuka dengan jenis tanah Organosol atau tanah gambut (Arsip Desa Ujung Said, 2014). Tujuan penelitian ini adalah mengetahui jenisjenis rotan apa saja yang ditemukan pada kawasan Hutan Lindung Danau Selogan Kalimantan Barat.

\section{BAHAN DAN METODE}

Penelitian ini dilakukan di Desa Ujung Said, Kecamatan Jongkong, Kabupaten Kapuas Hulu, Kalimantan Barat, telah dilaksanakan pada bulan Maret 2021. Metode penelitian yang digunakan adalah metode deskriptif dan teknik pengambilan sampel secara purposive sampling dengan cara jelajah berbentuk zig-zag 5 meter ke kiri dan 5 meter ke kanan sepanjang 100 meter sebagai jalur jelajah. 


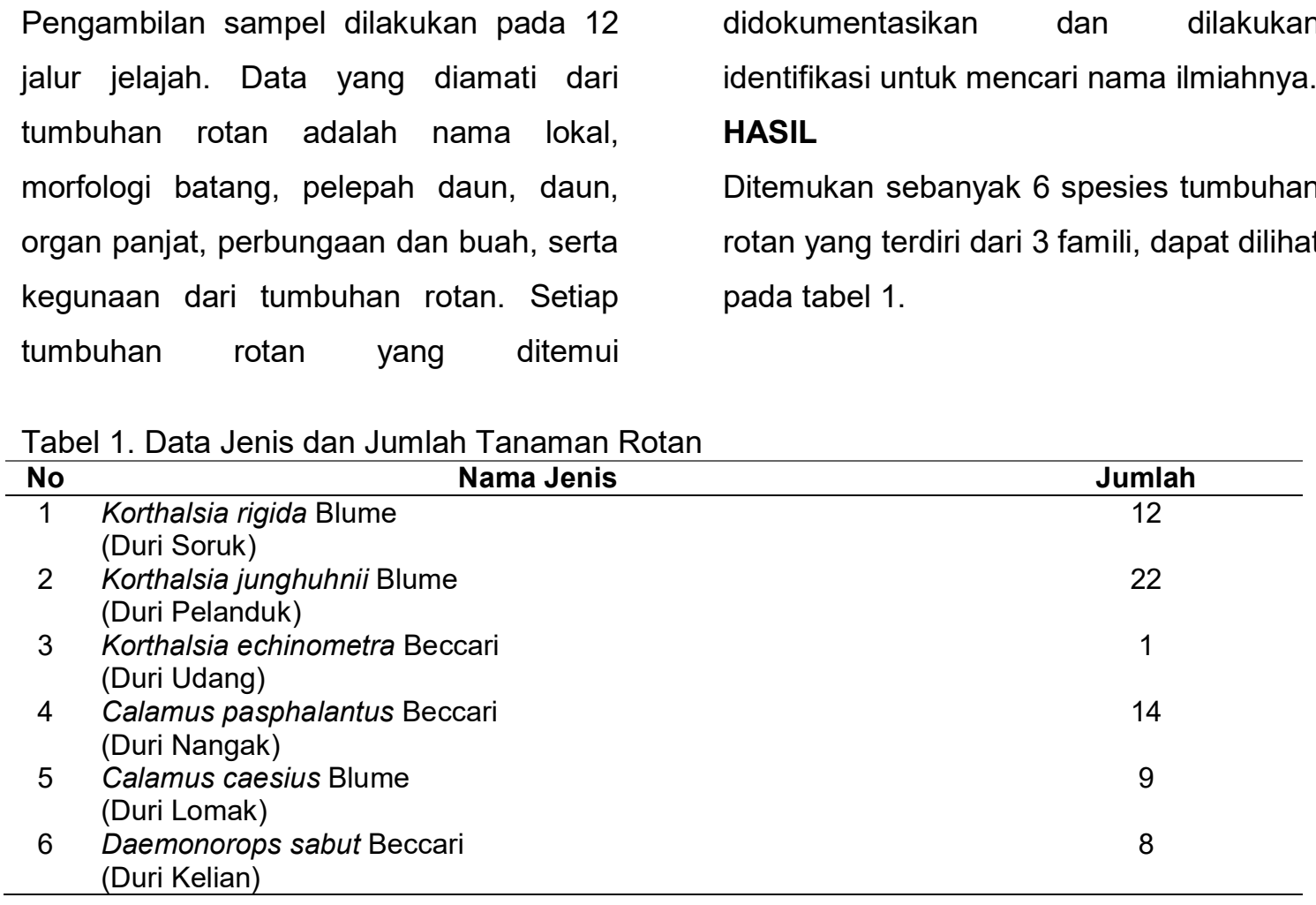

\section{PEMBAHASAN}

Berdasarkan hasil pengamatan dan identifikasi di lapangan pada 12 jalur jelajah di Hutan Lindung Danau Selogan, Desa Ujung Said, Kecamatan Jongkong,
Kabupaten Kapuas Hulu, Kalimantan Barat ditemukan 6 jenis rotan yang tergolong dari 3 genus yaitu Korthalsia, Calamus, Daemonorops, dapat dilihat pada tabel 2 .

Tabel 2. Nama jenis tumbuhan rotan

\begin{tabular}{clll}
\hline No & \multicolumn{1}{c}{ Nama Lokal } & \multicolumn{1}{c}{ Nama Jenis Rotan } & \multicolumn{1}{c}{ Nama Ilmiah } \\
\hline $\mathbf{1}$ & Duri Soruk & Rotan Marau & Korthalsia rigida Blume \\
$\mathbf{2}$ & Duri Pelanduk & Rotan Sampang & Korthalsia junghuhnii Blume \\
$\mathbf{3}$ & Duri Undang & Rotan Udang & Korthalsia echinometra Beccari \\
$\mathbf{4}$ & Duri Nangak & Rotan Sanjat & Calamus pasphalantus Beccari \\
$\mathbf{5}$ & Duri Lomak & Rotan Sega & Calamus caesius Blume \\
$\mathbf{6}$ & Duri Kelian & Rotan Sabut & Daemonorops sabut Beccari \\
\hline
\end{tabular}


Deskripsi jenis-jenis rotan tersebut yakni:

$\begin{array}{ll}\text { Rotan Marau } & \text { (Korthalsia rigida Blume) } \\ \text { Kingdom } & \text { : Plantae } \\ \text { Divisi } & \text { : Magnoliophyta } \\ \text { Kelas } & \text { : Liliopsida } \\ \text { Ordo } & \text { : Arecales } \\ \text { Family } & \text { : Arecaceae } \\ \text { Genus } & \text { : Korthalsia } \\ \text { Spesies } & \text { : Korthalsia rigida Blume } \\ \text { Nama Lokal } & \text { : Duri soruk }\end{array}$

Tanaman rotan marau tumbuh secara berumpun, memanjat dan bercabang pada kanopi hutan tinggi mencapai $16 \mathrm{~m}$. Batang rotan ini memiliki diameter dengan pelepah 2,3 $\mathrm{cm}$ dan diameter tanpa pelepah $2 \mathrm{~cm}$, panjang antar ruas batang $30 \mathrm{~cm}$, berwarna hijau dan permukaan licin. Pelepah daun berwarna cokelat dengan daun berwarna hijau pudar dan ditumbuhi banyak indumentum serta duri berwarna cokelat keabu-abuan, duri berbentuk segitiga dengan panjang 0,5-1 cm. duri tersebar di permukaan pelepah daun tersusun tidak terlalu rapat. Tidak memilii lutut. Okrea sangat jelas, panjangnya mencapai $10 \mathrm{~cm}$ melekat pada pelepah daun. Dalam okrea dihuni semut hitam dan dapat berbunyi jika ada gangguan dari luar. Rotan marau ini memiliki ibu tangkai dengan panjang $100 \mathrm{~cm}$ ditambah dengan adanya sirus sebagai alat panjat dengan panjang $65 \mathrm{~cm}$ dan terdapat duri-duri yang mengelompok. Helaian anan daun berbentuk rhomboid (belah ketupat) dengan warna bagian atas hijau muda dan bagian bawahnya abu-abu. Ciri-ciri tumbuhan rotan marau ini sesuai dengan deskripsi yang diutarakan oleh Jasni (2012).

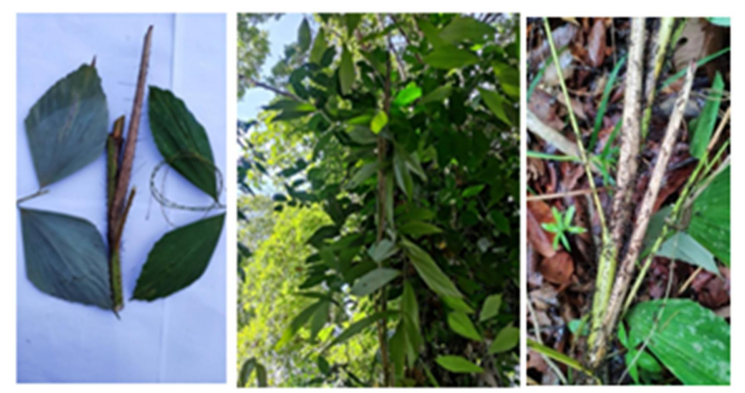

Gambar 1. Rotan Marau

\section{Rotan Sampang (Korthalsia junghuhnii Blume) \\ Kingdom : Plantae \\ Divisi : : Magnoliophyta \\ Kelas : Liliopsida \\ Ordo : Arecales \\ Family : Arecaceae \\ Genus : Korthalsia \\ Spesies : Korthalsia junghuhnii Blume \\ Nama Lokal : Duri pelanduk}

Rotan sampang tumbuh secara berumpun dengan lebat dan sering bercabang tinggi dalam hutan sehingga mengakibatkan belitan besar. Hal yang sama juga diutarakan oleh Santoso (2017) pada jenis Korthalsia Junghuhnii memiliki ciri yaitu jenis ini tumbuh berumpun dengan lebat dan sering bercabang tinggi dalam tajuk hutan sehingga mengakibatkan belitan besar, batang mencapai panjang $8 \mathrm{~m}$. Batang rotan sampang memiliki diameter dengan pelepah $2 \mathrm{~cm}$ dan tanpa pelepah berdiameter $1,5 \mathrm{~cm}$, panjang antar ruas batang $36 \mathrm{~cm}$ berwarna kecoklatan dengan permukaan licin. Pelepah daun berwarna hijau ditumbuhi duri berbentuk segitiga pipih yang tumbuh tidak beraturan dan jarang, duri berwarna kekuningan dengan panjang 0,5-1 cm. panjang ibu tangkai daun $60 \mathrm{~cm}$ dan memiliki sirus panjang $70 \mathrm{~cm}$ dengan duri yang berkelompok. Helaian anak daun berbentuk rhomboid bersusun majemuk menyirip dan permukaan daun halus. Ciri-ciri diatas juga diperkuat oleh jasni (2012). 

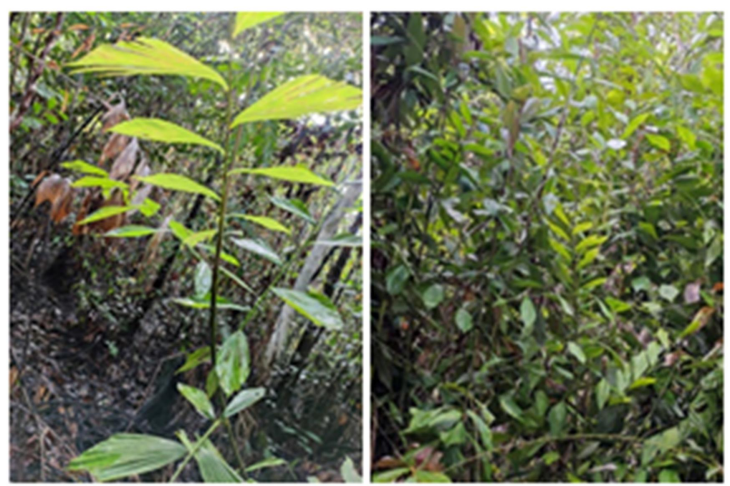

Gambar 2. Rotan Sampang

$\begin{array}{ll}\text { Rotan Udang (Korthalsia echinometra } \\ \text { Beccari) } & \\ \text { Kingdom } & \text { : Plantae } \\ \text { Divisi } & \text { : Magnoliophyta } \\ \text { Kelas } & \text { : Liliopsida } \\ \text { Ordo } & \text { : Arecales } \\ \text { Family } & \text { : Arecaceae } \\ \text { Genus } & \text { : Korthalsia } \\ \text { Spesies } & \text { : Korthalsia echinometra } \\ \text { Beccari } & \\ \text { Nama Lokal } & \text { : Duri undang }\end{array}$

Rotan udang tumbun secara berumpun, memanjat dan bercabang pada kanopi hutan. Batang berdiameter beserta pelepah $3 \mathrm{~cm}$ jika tanpa pelepah berdiameter $2 \mathrm{~cm}$ dan panjang antar ruas $25 \mathrm{~cm}$. pelepah daun berwarna hijau, ditumbuhi okrea dengan bentuk menggelembung tiap ruas dan di dalam okrea menjadi sarang bagi semut. Pelepah ditumbuhi duri rapat dan berbentuk segitiga pipih bewarna hitam dengan ukuran $2-5 \mathrm{~cm}$. panjang ibu tangkai daun $185 \mathrm{~cm}$ dan memiliki alat panjat berupa sirus dengan panjang 71 $\mathrm{cm}$. Helaian anak daun berbentuk rhomboid permukaan halus, susunan anak daun majemuk menyirip. Deskripsi tumbuhan rotan udang ini sesuai dengan deskripsi yang diutarakan oleh Jasni (2012).

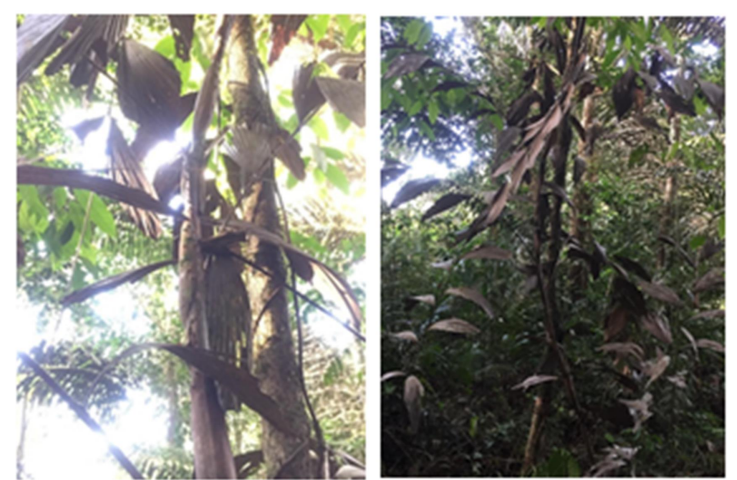

Gambar 3. Rotan Udang

$\begin{array}{ll}\begin{array}{l}\text { Rotan Sanjat } \\ \text { Beccari) }\end{array} & \text { Calamus pasphalantus } \\ \text { Kingdom } & \text { : Plantae } \\ \text { Divisi } & \text { : Magnoliophyta } \\ \text { Kelas } & \text { : Liliopsida } \\ \text { Ordo } & \text { : Arecales } \\ \text { Family } & \text { : Arecaceae } \\ \text { Genus } & \text { : Calamus } \\ & \text { Spesies : Calamus } \\ & \text { pasphalantus } \\ & \text { Beccari } \\ \text { Nama Lokal } & \text { : Duri nangak }\end{array}$

Rotan sanjat tumbuh secara soliter atau tunggal, menyukai tepian sungai untuk hidup, memanjat lebih dari $20 \mathrm{~m}$, memiliki diameter batang dengan pelepah $3,5 \mathrm{~cm}$ sedangkan diameter tanpa pelepah hanya $1 \mathrm{~cm}$, memiliki panjang atar ruas $14 \mathrm{~cm}$, batang berwarna hijau kekuningan dengan permukaan halus. Pelepah daun hijau pudar yang ditumbuhi duri dengan bentuk segitiga pipih berwarna hitam berukuran $4 \mathrm{~cm}$, duri tersebar di permukaan pelepah secara tidak teratur dan rapat. Terdapat lutut yang sangat jelas. Rotan sanjat memiliki ibu tangkai daun dengan panjang 80 $\mathrm{cm}$ dan memiliki sirus dengan panjang $100 \mathrm{~cm}$ dengan duri yang berkelompok terdiri dari 2 buah duri menghadap belakang. anak daun berbentuk pita tersusun menyirip teratur dengan panjang $30 \mathrm{~cm}$, permukaan helaian anak daun bagian atas berwarna hijau dan bagian bawah hijau keabu-abuan Jasni (2012).

Jenis Calamus Pasphalantus merupakan yang paling sering dijumpai, genus ini dapat tumbuh dari daerah rendah sampai daerah yang cukup tinggi, tetapi jenis ini lebih banyak ditemukan didaerah yang cukup ternaungi dan disepanjang daerah pinggiran sungai. Ciri 
umum untuk mengenal genus ini adalah batang yang berukusan besar dan memanjat (Santoso, 2017).

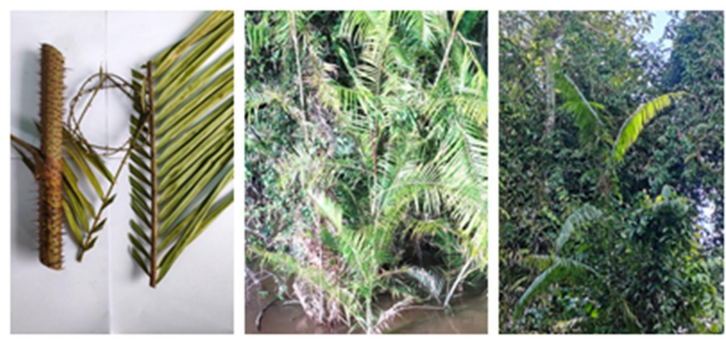

Gambar 4. Rotan Sanjat

$\begin{array}{ll}\text { Rotan Sega } & \text { (Calamus caesius Blume) } \\ \text { Kingdom } & \text { : Plantae } \\ \text { Divisi } & \text { : Magnoliophyta } \\ \text { Kelas } & \text { : Liliopsida } \\ \text { Ordo } & \text { : Arecales } \\ \text { Family } & \text { : Arecaceae } \\ \text { Genus } & \text { : Calamus } \\ \text { Spesies } & \text { : Calamus caesius Blume } \\ \text { Nama Lokal } & \text { : Duri lomak }\end{array}$

Rotan sega tumbuh secara berumpun, memanjat sampai kanopi hutan dengan ketinggian kurang lebih $20 \mathrm{~m}$. batang bulat dengan diameter beserta pelepah 0,9-2 cm dan diameter tanpa pelepah 0,7-1,2 cm, pelepah daun memiliki lutut yang jelas dengan panjang ruas $42 \mathrm{~cm}$ dengan warna hijau tua dan permukaan halus. Pelepah daun berwarna hijau tua, ditumbuhi duri yang menyebar pada pelepah, duri berbentuk segitiga pipih pendek dengan ukuran $0,2-0,5 \mathrm{~cm}$, duri lemah dan mudah gugur berwarna cokelat kehitaman. Panjang ibu tangkai daun $70 \mathrm{~cm}$ dan ditumbuhi duri namun berkelompok, bentuk anak daun pita lanset dengan susunan menyirip berkelompok serta permukaan daun halus. Alat panjat rotan ini yaitu sirus dengan panjang $75 \mathrm{~cm}$ yang ditumbuhi duri pada bagian bawah secara berkelompok (Jasni, 2010).

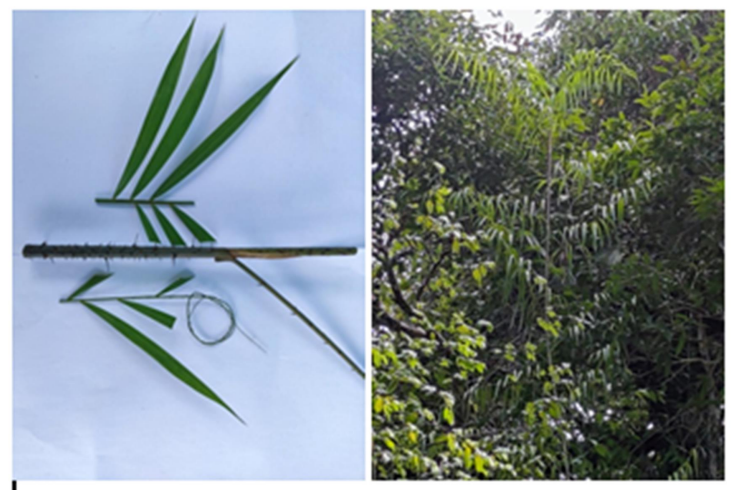

Gambar 5. Rotan Sega

$\begin{array}{ll}\text { Rotan Sabut } & \text { (Daemonorops sabut Beccari) } \\ \text { Kingdom } & \text { : Plantae } \\ \text { Divisi } & \text { : Magnoliophyta } \\ \text { Kelas } & \text { : Liliopsida } \\ \text { Ordo } & \text { : Arecales } \\ \text { Family } & \text { : Arecaceae } \\ \text { Genus } & \text { : Daemonorops } \\ \text { Spesies } & \text { : Daemonorops sabut Beccari } \\ \text { Nama Lokal } & : \text { Duri kelian }\end{array}$

Rotan sabut tumbuh secara berumbun dan memanjat sampai ketinggian $40 \mathrm{~m}$. rotan ini memiliki batang yang berukuran kecil dengan diameter beserta pelepah $2,5 \mathrm{~cm}$ dan diameter tanpa pelepah 1,5-2 cm, panjang antar ruas 10 $\mathrm{cm}$, batang berwarna hijau kekuningan dengan permukaan licin. Pelepah daun berwana hijau dengan ditumbuhi kolar (kerah) yang bagian ujungnya ditumbuhi duri seperti rambut berwarna cokelat kehitaman dengan panjang 4-5 cm, diantara kolar membentuk rongga dan menjadi sarang untuk semut. Ciri-ciri ini sesuai dengan deskripsi Santoso (2017) menyatakan rotan sabut ditumbuhi kolar-kolar berukuran 10 $\mathrm{mm}$, ujung kolar ditumbuhi rambut seperti duri berwarna coklat kehitaman. Terdapat lutut yang jelas, memiliki ibu tangkai daun dengan panjang $150 \mathrm{~cm}$ dan memiliki sirus dengan panjang $60 \mathrm{~cm}$, terdapat duri yang berkelompok dan menghadap ke belakang berfungsi sebagai pengait. Helaian anak daun berbentuk pita tersusun menyirip tidak teratur, helaian anak daun berwarna hijau pada bagian atas dan bawah. Saputra (2019) menyebutkan bahwa rotan sabut memiliki ciri-ciri daun berbentuk seperti daun kelapa, bagian beranak daun memiliki panjang $100-200 \mathrm{~cm}$, panjang sirus $50-100 \mathrm{~cm}$. Duri pelepah melingkar dan terdiri atas duri-duri panjang yang halus berwarna cokelat kehitaman, 
panjang duri 2-4 cm, (Jasni, 2010).

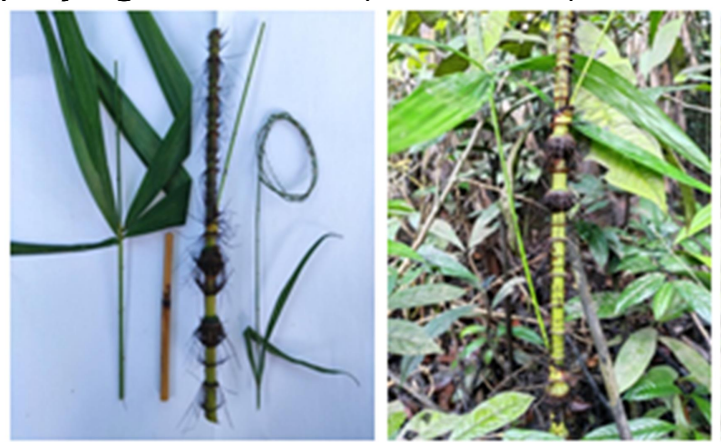

Gambar 6. Rotan Sabut

DAFTAR PUSTAKA

Arsip Desa Ujung Said. 2014. Kumpulan Jenis Rotan di Desa Ujung Said. (tidak diterbitkan)

Januminro, C. F. M. 2000. Rotan Indonesia: Potensi, Budidaya, Pemungutan, Pengolahan, Standar Mutu, dan Prospek Pengusahaan. Yogyakarta: Kanisius

Jasni, Krisdianto, Kalima, T., Abdurachman. 2012. Atlas Rotan Indonesia Jilid 3.

Bogor: Pusat Penelitian dan Pengembangan Ketenikan Kehutanan dan Pengolahan Hasil Hutan. Badan Penelitian dan Pengembangan Kehutanan Kementrian Kehutanan

Jasni, Damayanti, R., Kalima, T. 2012. Atlas Rotan Indonesia Jilid 1. Bogor: Pusat Penelitian dan Pengembangan Ketenikan Kehutanan dan Pengolahan Hasil Hutan. Badan Penelitian dan Pengembangan Kehutanan Kementrian Kehutanan

Jasni, Damayanti, R., Kalima, T., Malik, J., Abdurachman. 2010. Atlas Rotan Indonesia Jilid 2. Bogor: Pusat Penelitian dan Pengembangan Ketenikan Kehutanan dan Pengolahan Hasil Hutan. Badan
Penelitian dan Pengembangan Kehutanan Kementrian Kehutanan

Santoso, E., Fahrizal, Ardian, H. 2017. Identifikasi Jenis Rotan di Kecamatan Selimbau Kawasan Taman Nasional Danau Sentarum. Jurnal Tengkawang, 7 (1)

Saputra, N. G., Idham M., Yani, A. 2019. Identifikasi Jenis Rotan di Kawasan Hutan Adat Dusun Ensibau Desa Semirau Kecamatan Jangkang Kabupaten Sanggau. Jurnal Hutan Lestari, 7 (2),723-730

Sujoko. 2013. Pendugaan Potensi Rotan di Kawasan Hutan Produksi Terbatas (HPT) Kelompok Hutan Sungai Tenungun Kecamatan Bunut Hulu Kabupaten Kapuas Hulu Kalimantan Barat. Jurnal Hutan Lestari, 7 (2), 